\title{
Methylphenidate for Treating ADHD: A Naturalistic Clinical Study of Methylphenidate Blood Concentrations in Children and Adults With Optimized Dosage
}

\author{
Maria D. Chermá ${ }^{1,2}$ - Martin Josefsson ${ }^{1,3} \cdot$ Irene Rydberg $^{4} \cdot$ Per Woxler $^{5}$ \\ Tomas Trygg ${ }^{5} \cdot$ Olle Hollertz $^{6} \cdot$ Per A. Gustafsson ${ }^{7}$
}

Published online: 25 May 2016

(C) The Author(s) 2016. This article is published with open access at Springerlink.com

\begin{abstract}
Background Methylphenidate (MPH), along with behavioral and psychosocial interventions, is the first-line medication to treat attention-deficit hyperactivity disorder (ADHD) in Sweden. The dose of MPH for good symptom control differs between patients. However, studies of MPH concentration measurement in ADHD treatment are limited.

Objective To describe blood and oral fluid (OF) concentrations of MPH after administration of medication in patients with well-adjusted MPH treatment for ADHD, and
\end{abstract}

Maria D. Chermá

maria.dolores.cherma.yeste@ regionostergotland.se

1 Department of Forensic Genetics and Forensic Toxicology, National Board of Forensic Medicine, Linköping, Sweden

2 Department of Clinical Pharmacology and Department of Medical and Health Sciences, Linköping University, Linköping, Sweden

3 Department of Physics, Chemistry and Biology, Linköping University, Linköping, Sweden

4 Department of Medical and Health Sciences, Linköping University, Linköping, Sweden

5 Department of Dependency, Linköping University Hospital, Linköping, Sweden

6 Department of General Psychiatry, Västervik Hospital, Västervik, Sweden

7 Center for Social and Affective Neuroscience Department of Clinical and Experimental Medicine and Department of Child and Adolescent Psychiatry, Linköping University, Linköping, Sweden to identify the most suitable matrix for accurate MPH concentration during treatment.

Methods Patients were recruited from Child and Adolescent Psychiatry (CAP), General Psychiatry (GP), and the Department of Dependency (DD). Blood and OF samples were collected in the morning before MPH administration as well as 1 and $6 \mathrm{~h}$ after administration of the prescribed morning dose of MPH.

Results Fifty-nine patients aged between 9 and 69 years, $76 \%$ males. The daily dose of MPH varied from 18 to $180 \mathrm{mg}$, but the median daily dose per body weight was similar, approximately $1.0 \mathrm{mg} / \mathrm{kg}$ body weight. The median MPH concentration in blood 1 and $6 \mathrm{~h}$ after the morning dose was 5.4 and $9.3 \mathrm{ng} / \mathrm{mL}$, respectively. Highly variable OF-to-blood ratios for MPH were found at all time points for all three groups.

Conclusions Weight is a reliable clinical parameter for optimal dose titration. Otherwise, MPH blood concentration might be used for individual dose optimization and for monitoring of the prescribed dose. Relying only on the outcome in OF cannot be recommended for evaluation of accurate MPH concentrations for treatment monitoring. 


\section{Key Points}

The variability of the administered MPH dose (mg/ $\mathrm{kg}$ ) between patients was large. However, the median daily dose of MPH per kg body weight was similar for all ages, approximately $1.0 \mathrm{mg} / \mathrm{kg}$ body weight. Thus, adults, as they normally weigh more than children, require higher doses of MPH per day than children do.

After the morning dose of OROS-MPH, the median MPH concentration (25th and 75th percentiles) in blood was 5.4 (3.8-7.7) $\mathrm{ng} / \mathrm{mL}$ after $1 \mathrm{~h}$ and 9.3 (6.6-13) $\mathrm{ng} / \mathrm{mL}$ after $6 \mathrm{~h}$. Relying only on oral fluid samples cannot be recommended for evaluation of accurate MPH concentrations for treatment monitoring.

Patients with a history of drug abuse did not require significantly higher doses of MPH to achieve good ADHD symptom control.

\section{Introduction}

Pharmacological treatment combined with behavioral and psychosocial interventions is an important part of a multimodal approach to treat attention-deficit hyperactivity disorder (ADHD) to enhance the patients' and parents' capability to cope with symptoms and behavioral problems, as well as to adapt the environment to the child's specific difficulties [1]. As in many other countries [2], there is a rise in Sweden in the use of ADHD medications: $2.7 \%$ of children (5-19 years old) and $0.9 \%$ of adults (20-65 years old) purchased a prescribed ADHD medication in 2015 [3]. Compared to 2006, this corresponds to a 4.4-fold increase in children and a 6.3 -fold increase in adults. The first-line drug treatment for ADHD in Sweden is methylphenidate (MPH) [3, 4, 5]: $70.1 \%$ of ADHD prescriptions for children and $66.2 \%$ for adults in 2015. Other prescribed drugs were atomoxetine $15.2 \%$ for children and $10.8 \%$ for adults as well as lisdexamphetamine $14.3 \%$ for children and $18.2 \%$ for adults.

MPH is rapidly and extensively metabolized in liver and other tissues by non-microsomal hydrolytic esterases, carboxylesterases (CES) [6-8] to its major and essentially inactive metabolite ritalinic acid (RA) [9]. The half-life of MPH ranges from 2 to $3 \mathrm{~h}$ both in adults and in children $[10,11]$.

In clinical experience, the optimal dose for good symptom control varies between patients. Clinical guidelines recommend a stepwise titration with careful monitoring of both beneficial and side effects [12]. Since MPH is a controlled drug with potential risk for abuse, prescription rates are monitored by Swedish authorities [13]. To this day, data on use of MPH concentration for therapy control in ADHD treatment are limited. The majority of the studies on pharmacokinetics (PK) of MPH concern healthy volunteers, and more infrequently, children [14-18]. One of the few studies concerning clinical use of MPH concentration examines medication adherence with the use of oral fluid (OF) as sampling matrix [19]. The few studies reporting blood concentrations of MPH have methodological limitations, such as small sample size and not rarely, vague diagnostic routines. It would be desirable to establish a correlation between MPH concentrations and good symptom control that does not rely only on subjective reports from patients (and in the case of children from parents and teachers) to improve treatment efficacy. Also, treatment of former drug abusers is a topic worth investigating.

The aim of this naturalistic study was to determine MPH concentrations (in blood and OF) in patients with welladjusted MPH treatment for ADHD. Patients include: children, adults with no history of drug abuse, and adults with former drug and/or alcohol abuse. An additional aim was to determine whether OF can be used to predict blood concentrations and thus be useful for monitoring of MPH treatment.

\section{Patients and Methods}

\subsection{Participants}

Patients were recruited from outpatient clinics in Child and Adolescent Psychiatry (CAP), General Psychiatry (GP), and the Department of Dependency (DD). Participants were informed about the study by their clinical doctor and asked if they wished to participate. Written informed consent was collected from all patients (for the children also from their parents). The participants received no financial compensation. Participation was voluntary and in no way affected MPH treatment.

Inclusion criteria were: DSM-IV ADHD diagnosis verified by an experienced clinician at CAP, GP or DD, chronic treatment with a prolonged release formulation of $\mathrm{MPH}$, and a clinically titrated optimal dose considered to provide good symptom control, i.e., a reduction of ADHD symptoms to level 2 on the 7-grade Clinical Global Impression-Severity scale. The dosing was optimized by careful clinical examination and in most cases monitored with the help of both questionnaires and computer-based assessment of core symptoms of ADHD: QbTest [20] or test of variables of attention (TOVA) [21] performed approximately $1-3 \mathrm{~h}$ after morning intake of MPH. The DD patients had been substance abuse free $\geq 3$ months (as 
tested with urinary samples), however, moderate alcohol use was accepted. Patients with comorbid autism spectrum disorder and/or moderate mental retardation were excluded. Also, poor dental status was an exclusion criterion (to avoid blood contamination in OF samples). Other psychiatric comorbidities, such as anxiety disorder and affective illness, were accepted.

\subsection{Methylphenidate Sampling}

On the appointed day, participants were instructed not to take their morning dose of MPH at home. If they normally were taking more than a morning dose of MPH, they were instructed not to take that dose on the previous day as well as during the study day. Samples were collected at the Department of Psychiatry at Oskarshamn Hospital, the Department of Psychiatry at Västervik Hospital, the Department of Drug Dependence at the University Hospital Linköping, the Department of Psychiatry at the University Hospital Linköping, the Department of Psychiatry at Ryhov County Hospital Jönköping, and for the children, at the Clinical Pharmacological Department at the University Hospital Linköping. Blood and OF were collected in the morning upon arrival as trough concentration (time 0 ). The participants subsequently took their prescribed morning dose of MPH, and two further samples were taken after 1 (time 1) and 6 (time 6) hours, since the prolonged release formulation of MPH has expected peak blood concentrations approximately $1-2$ and 5-7 h post-dose [22]. A specifically designed request form was used to acquire relevant clinical data on the patient at the time of sampling.

Blood samples were collected in Venosafe ${ }^{\circledR}$ plastic tubes containing Na-Fluoride/Na-Heparin. For OF collection, Salivette ${ }^{\circledR}$ plastic tubes containing a cotton wool swab were used. All samples aliquoted and stored at $-20{ }^{\circ} \mathrm{C}$ before transportation to the laboratory for long time storage at $-70{ }^{\circ} \mathrm{C}$ until drug analysis of MPH and RA metabolite were performed. Drug-free blood collected from healthy volunteers was purchased from the local University Hospital (Linköping, Sweden). Drug-free OF was obtained from laboratory staff volunteers.

\subsection{Analysis}

Blood and OF samples were analyzed by liquid chromatography tandem-mass spectrometry (ESI-LC-MS/MS) according to a previously described procedure [23]. The instrumentation consisted of an Acquity Ultra High Performance Liquid Chromatographic (UHPLC) system (Waters, Milford, MA, USA) and an API 4000 tandem quadrupole instrument equipped with an electrospray interface operating in positive ion mode (Applied Biosystem/MSD Sciex, Stockholm, Sweden). Chromatography was carried out on a Synergi Polar-RP $50 \times 2 \mathrm{~mm}$ i.e., $2.5 \mu \mathrm{m}$ column (Phenomenex, Torrance, CA, USA). Data were recorded by scheduled multiple reaction monitoring (MRM), including the two most intense transitions for MPH, RA, and the internal standards MPH-D9 and RAD10. Samples $(100 \mu \mathrm{l}$ blood or OF) were prepared by protein precipitation before analysis. The range of quantifications was $0.20-30 \mathrm{ng} / \mathrm{mL}$ for $\mathrm{MPH}$ and $10-1500 \mathrm{ng} /$ $\mathrm{mL}$ for RA in blood as well as $1-500 \mathrm{ng} / \mathrm{mL}$ for MPH and $0.25-125 \mathrm{ng} / \mathrm{mL}$ for RA in OF. Low and high concentration control samples were analyzed in each run. For MPH, the between-day precision $(\mathrm{CV})$ was equal to or better than $10 \%$ in both blood and OF, while the precision for RA was equal to or better than $15 \%$. The accuracy was within 90-110\% for control concentrations in blood and OF.

\subsection{Statistical Analyses}

Median values, the 25 th and 75 th percentiles, mean values, and range were computed. Besides descriptive statistics, covariations between variables were analyzed using the Spearman rank correlation coefficient $\left(r_{\mathrm{s}}\right)$. For comparisons between two groups, the Mann-Whitney $U$ test was used (unevenly distributed data). For multiple comparisons, the Kruskal-Wallis test was performed. Sign test and Friedman ANOVA were used for comparing dependent variables. Statistical significance was predefined as $p<0.05$ (2tailed). The coefficient of variation (CV) was used to estimate inter-individual variability. Data points below the limit of quantification (LOQ) were excluded from the calculations. The computer software STATISTICA 10 (StatSoft, Inc., USA) was used for the statistical computations.

Dose normalization: to enable the comparison among patients who had taken different doses of MPH, the blood concentrations of MPH and the RA metabolite were normalized against the ratio of morning dose to body weight. Proportional dose-concentration linearity was assumed. The concentration-to-dose per weight $[C /(D /$ weight $)]$ acquired in this way approximates the drug concentration in $\mathrm{ng} / \mathrm{mL}$ per $\mathrm{mg}$ of administered drug and $\mathrm{kg}$ body weight $[(\mathrm{ng} / \mathrm{mL}) /(\mathrm{mg} / \mathrm{kg})]$.

\section{Results}

A total of 59 patients were enrolled into the study: 38 adults (22 patients from GP and 16 patients from DD) and 21 children from CAP. For demographics and baseline characteristics, see Tables 1 and 2 . The majority of subjects were male (76\%), almost all had ADHDcombined type $(97 \%)$ and had normal or above average intelligence (95\%). Ninety-five percent of the adults had 
Table 1 Demographic and baseline characteristics from the medical record

\begin{tabular}{|c|c|c|c|c|}
\hline & GP & $\mathrm{DD}$ & CAP & All patients \\
\hline Number $(n)$ of patients & 22 & 16 & 21 & 59 \\
\hline \multicolumn{5}{|l|}{ Gender, $n$} \\
\hline Male & 14 & 11 & 20 & 45 \\
\hline Female & 8 & 5 & 1 & 14 \\
\hline \multicolumn{5}{|l|}{ Age $(y)$, median (range) } \\
\hline All & $39(18-67)$ & $46(21-69)$ & $12(9-17)$ & $33(9-69)$ \\
\hline Male & $38(18-67)$ & $48(21-69)$ & $12(9-17)$ & $24(9-69)$ \\
\hline Female & $42(19-52)$ & $35(27-58)$ & 10 & $39(10-58)$ \\
\hline \multicolumn{5}{|l|}{ ADHD type, $n$} \\
\hline $\mathrm{ADD}$ & 0 & 1 & 1 & 2 \\
\hline ADHD-combined & 22 & 15 & 20 & 57 \\
\hline \multicolumn{5}{|l|}{ Intelligence Quotient estimate, $n$} \\
\hline Above average intelligence & 0 & 2 & 1 & 3 \\
\hline Normal or average intelligence & 22 & 14 & 17 & 53 \\
\hline Lower normal range & 0 & 0 & 3 & 3 \\
\hline \multicolumn{5}{|l|}{ School education, $n$} \\
\hline Regular classes without support person & 22 & 14 & 3 & 39 \\
\hline Regular classes with support person & 0 & 1 & 14 & 15 \\
\hline Special school & 0 & 1 & 4 & 5 \\
\hline \multicolumn{5}{|l|}{ Treatment history, mean (range) } \\
\hline Age (y) first entered treatment & $39(18-65)$ & $43(21-67)$ & $10(6-16)$ & $30(6-67)$ \\
\hline Time $(\mathrm{m})$ for treatment & $15(4-44)$ & $21(4-76)$ & $33(4-69)$ & $23(4-76)$ \\
\hline Time $(\mathrm{m})$ for treatment with present dose & $14(3-44)$ & $13(1-38)$ & $15(2-35)$ & $14(1-44)$ \\
\hline \multicolumn{5}{|l|}{ Previous/concurrent psychiatric diagnoses, $n$} \\
\hline None & 15 & 5 & 17 & 37 \\
\hline Language disorder & 0 & 0 & 3 & 3 \\
\hline Pervasive developmental disorder & 1 & 0 & 1 & 2 \\
\hline Anxiety/depression & 6 & 11 & 0 & 17 \\
\hline \multicolumn{5}{|l|}{ Previous drug abuse ("preferred drug"), $n$} \\
\hline None & 19 & 0 & 21 & 40 \\
\hline Amphetamines & 0 & 8 & 0 & 8 \\
\hline Alcohol & 3 & 7 & 0 & 10 \\
\hline Heroin & 0 & 1 & 0 & 1 \\
\hline
\end{tabular}

$y$ years, $m$ months, GP General Psychiatry, $D D$ Department of Dependency, CAP Child and Adolescent Psychiatry, $A D H D$ attention-deficit hyperactivity disorder, $A D D$ attention-deficit disorder received no special help in school in contrast to the great majority of the children $(86 \%)$. The mean MPH treatment length was almost 2 years, and the mean time on the present dose of MPH was just over 1 year. Among the adults, $47 \%$ had another previous/concurrent psychiatric diagnosis while this was the case for only $19 \%$ of the children.

All patients from DD had a history of previous mixed drug abuse. The "preferred drug of abuse" was alcohol in $44 \%$ of the cases and intravenous drugs (mostly amphetamines) in $56 \%$. Among patients from GP, $14 \%$ had a history of previous alcohol abuse. No child had any reported drug abuse.
The majority of the adults had other concomitant pharmacological treatment $(76 \%)$ while this was the case in only a minority of the children (14\%). Among the adults, $50 \%$ was taking at least one central nervous system (CNS)-active drug [categorized as " $\mathrm{N}$ " according to the Anatomical Therapeutic Chemical (ATC) Classification system]. The most common co-medications were antidepressants (N06A, $n=15$ patients, e.g. sertraline or citalopram) as well as anxiolytics, sedatives, and hypnotic drugs (N05B, $n=7$ patients, e.g., diazepam or oxazepam; N05C, $n=7$ patients, e.g., propiomazine or melatonine). The most frequent "somatic" drugs (categorized according to the other ATC groups, beyond "N") were drugs for the 
Table 2 Baseline characteristics from the request forms

\begin{tabular}{|c|c|c|c|c|}
\hline & GP & DD & CAP & All patients \\
\hline \multicolumn{5}{|c|}{ Current daily dose (mg/day), median (range) } \\
\hline All & $72(18-180)$ & $90(36-180)$ & $50(27-74)$ & $72(18-180)$ \\
\hline Male & $81(18-180)$ & $90(36-180)$ & $50(27-74)$ & $54(18-180)$ \\
\hline Female & $72(27-126)$ & $90(72-126)$ & 36 & $72(27-126)$ \\
\hline \multicolumn{5}{|l|}{ Dose regimen, $n$} \\
\hline Once a day & 9 & 10 & 16 & 35 \\
\hline Twice daily & 10 & 6 & 4 & 20 \\
\hline Three times a day & 3 & 0 & 1 & 4 \\
\hline \multicolumn{5}{|l|}{ Weight (kg), median (range) } \\
\hline All & $82(57-122)$ & $84(64-138)$ & $35(30-90)$ & $72(30-138)$ \\
\hline \multicolumn{5}{|c|}{ Daily dose to weight (mg/kg), median (range) } \\
\hline All & $1.1(0.18-2.2)$ & $1.0(0.43-1.9)$ & $1.0(0.60-2.2)$ & $1.0(0.18-2.2)$ \\
\hline Male & $1.1(0.18-2.0)$ & $1.0(0.43-1.8)$ & $1.0(0.60-2.2)$ & $1.0(0.18-2.2)$ \\
\hline Female & $1.1(0.41-2.2)$ & $1.1(0.86-1.9)$ & 1.1 & $1.1(0.41-2.2)$ \\
\hline \multicolumn{5}{|l|}{ Concomitant medication, $n$} \\
\hline MPH only ${ }^{a}$ & 6 & 3 & 18 & 27 \\
\hline $\mathrm{MPH}+\mathrm{CNS}^{\mathrm{b}}$ & 12 & 7 & 3 & 22 \\
\hline $\mathrm{MPH}+1$ drug $^{\mathrm{c}}$ & 7 & 2 & 2 & 11 \\
\hline $\mathrm{MPH}+\geq 2$ drugs $^{\mathrm{c}}$ & 9 & 11 & 1 & 21 \\
\hline \multicolumn{5}{|l|}{ Other medication, $n$} \\
\hline Herbal medicine & 4 & 6 & 1 & 11 \\
\hline Temporally/local treatment & 9 & 8 & 6 & 23 \\
\hline \multicolumn{5}{|l|}{ Nicotine, $n$} \\
\hline Yes, daily & 13 & 13 & 0 & 26 \\
\hline$>10 \mathrm{mg}$ & 9 & 6 & - & 15 \\
\hline \multicolumn{5}{|l|}{ Caffeine, $n$} \\
\hline Yes, daily & 19 & 15 & 7 & 41 \\
\hline$>0.5 \mathrm{~g}$ & 6 & 9 & 0 & 15 \\
\hline \multicolumn{5}{|l|}{ Present alcohol consumption, $n$} \\
\hline Yes & 16 & 9 & 0 & 25 \\
\hline Daily & 4 & 3 & - & 7 \\
\hline Large consumption & 6 & 4 & - & 10 \\
\hline
\end{tabular}

GP General Psychiatry, $D D$ Department of Dependency, $C A P$ Child and Adolescent Psychiatry, $M P H$ methylphenidate, $R A$ ritalinic acid

${ }^{a}$ MPH monotherapy

b Co-medication with CNS-active drugs

c Co-medication with CNS-active drug or "somatic" drug

alimentary tract and metabolism ("A", $n=10$ patients, e.g., omeprazole or metphormine) as well as for the cardiovascular system ("C", $n=8$ patients, e.g. metoprolol or enalapril). The majority of adults (53\%) had at least two drugs beyond MPH treatment. No patient was being treated with neuroleptics.

None of the children were smokers, while $68 \%$ of the adults smoked daily. Daily caffeine consumption (coffee or soft drinks) was reported by $89 \%$ of adults and $33 \%$ of children. The majority of the adults used alcohol, $26 \%$ had a large consumption, i.e., more than one glass of wine for women or two glasses of wine for men per day.

The daily dose of MPH varied from 18 to $180 \mathrm{mg}$. Thirty-five patients were prescribed MPH once a day in the morning, while 24 patients had more than one daily dose. The median daily dose was significantly lower $(p<0.001)$ in children than in adults, 50 and $81 \mathrm{mg}$, respectively, while the median daily dose per $\mathrm{kg}$ body weight was the same (approximately $1.0 \mathrm{mg} / \mathrm{kg}$ ) in all three groups $(p=0.89)$. 
Table 3 Methylphenidate analysis in blood

\begin{tabular}{|c|c|c|c|c|}
\hline & GP & $\mathrm{DD}$ & CAP & All patients \\
\hline \multicolumn{5}{|l|}{ All participants } \\
\hline Number $(n)$ of patients & 22 & 16 & 21 & 59 \\
\hline Male:Female $(n)$ & $14: 8$ & $11: 5$ & $20: 1$ & $45: 14$ \\
\hline Age (y) & $39(18-67)$ & $46(21-69)$ & $12(9-17)$ & $33(9-69)$ \\
\hline \multicolumn{5}{|l|}{ Trough sampling times ${ }^{\mathrm{a}}(\mathrm{h})$} \\
\hline time 0 & $24.2(19.9-27.8)$ & $25.3(18.7-27.9)$ & $24.5(14.9-25.9)$ & $24.9(14.9-27.9)$ \\
\hline \multicolumn{5}{|c|}{ Blood concentration at time 0 (trough concentration) } \\
\hline MPH ng/ml & $0.59\left(<0.20^{\mathrm{c}}-16\right)$ & $0.90\left(<0.20^{\mathrm{c}}-4.1\right)$ & $0.70\left(<0.20^{\mathrm{b}}-1.9\right)$ & $0.63\left(<0.20^{\mathrm{e}}-16\right)$ \\
\hline $\mathrm{RA} \mathrm{ng} / \mathrm{ml}$ & $177(14-671)$ & $168(15-290)$ & $95(14-269)$ & $131(14-671)$ \\
\hline RA/MPH & $289(42-952)$ & $212(38-911)$ & $157(28-434)$ & $202(28-952)$ \\
\hline \multicolumn{5}{|c|}{ Patients with the osmotic release oral system (OROS)-MPH } \\
\hline Number $(n)$ of patients & 18 & 16 & 16 & 50 \\
\hline Male:Female $(n)$ & $11: 7$ & $11: 5$ & $15: 1$ & $37: 13$ \\
\hline Age (y) & $39(18-67)$ & $46(21-69)$ & $12(9-17)$ & $34(9-69)$ \\
\hline \multicolumn{5}{|c|}{ Blood concentration at time 0 (trough concentration) } \\
\hline MPH ng/ml & $0.49\left(<0.20^{\mathrm{c}}-2.3\right)$ & $0.90\left(<0.20^{\mathrm{c}}-4.1\right)$ & $0.70(0.35-1.9)$ & $0.65\left(<0.20^{\mathrm{d}}-4.1\right)$ \\
\hline $\mathrm{RA} n g / \mathrm{ml}$ & $118(14-599)$ & $168(15-290)$ & $94(14-269)$ & $126(14-599)$ \\
\hline RA/MPH & $289(97-953)$ & $213(38-911)$ & $135(28-267)$ & $189(28-953)$ \\
\hline Morning dose (mg) & $54(18-126)$ & $72(36-144)$ & $36(27-54)$ & $54(18-144)$ \\
\hline \multicolumn{5}{|c|}{ Blood concentration at time 1 ( $1 \mathrm{~h}$ after the morning dose) } \\
\hline MPH ng/ml & $5.2(1.1-16)$ & $7.1(3.3-18)$ & $5.6(0.30-13)$ & $5.8(0.30-18)$ \\
\hline $\mathrm{RA} \mathrm{ng} / \mathrm{ml}$ & $229(71-852)$ & $343(266-728)$ & $198(52-512)$ & $294(52-852)$ \\
\hline RA/MPH & $51(26-120)$ & $58(16-104)$ & $37(22-327)$ & $47(16-327)$ \\
\hline \multicolumn{5}{|c|}{ Blood concentration at time 6 ( $6 \mathrm{~h}$ after the morning dose) } \\
\hline MPH ng/ml & $7.6(2.2-25)$ & $10(2.9-20)$ & $13(5.7-22)$ & $10(2.2-25)$ \\
\hline $\mathrm{RA} n g / \mathrm{ml}$ & $425(104-1090)$ & $491(293-1100)$ & $396(213-511)$ & $427(104-1100)$ \\
\hline $\mathrm{RA} / \mathrm{MPH}$ & $52(26-102)$ & $54(20-119)$ & 34 (19-66) & $44(19-119)$ \\
\hline
\end{tabular}

Data are presented as median (range) unless specified otherwise

$G P$ General Psychiatry, DD Department of Dependency, CAP Child and Adolescent Psychiatry, $M P H$ methylphenidate, $R A$ ritalinic acid

a The time elapsed between the last administration and the sample collection

Data points below the LOQ were excluded from the calculations: number of patients $={ }^{\mathrm{b}} 2,{ }^{\mathrm{c}} 3,{ }^{\mathrm{d}} 6,{ }^{\mathrm{e}} 8$
MPH blood concentration at time 0 was very low (Table 3). Eight patients had concentrations below the LOQ (three patients in GP, three in DD, and two in CAP). One adult patient with MPH blood concentration at time 0 below the LOQ, reported on the study day that he could not remember if he took the previous morning dose of $72 \mathrm{mg}$ MPH. One adult treated with $60 \mathrm{mg}$ twice a day had a concentration of $16 \mathrm{ng} / \mathrm{mL}$. RA blood concentrations were quantifiable in all samples and were higher than MPH blood concentrations (30- to 3000-fold). No correlation $\left(r_{\mathrm{s}}=0.16, p=0.23\right)$ could be found between the dose taken the day before the study day and the trough blood concentration of MPH.

On the study day, 50 patients took osmotic release oral system (OROS)-MPH $\left(\right.$ Concerta $\left.^{\circledR}\right)$. The remaining nine patients took extended release MPH $\left(\right.$ Ritalin $^{\circledR}$ or
Medikinet ${ }^{\circledR}$ ). Five patients took an immediate release formulation of MPH (Ritalin ${ }^{\circledR}$ or Medikinet ${ }^{\circledR}$ ) as add-on to extended release formulations.

\subsection{OROS-Methylphenidate Patients}

To reduce data variability due to differences in drug formulation, only the patients that took OROS-MPH $(n=50)$ were considered for further analysis. The blood concentrations of MPH and RA of these patients are shown in Table 3. Six patients had concentrations below the LOQ at time 0 (three patients in GP and three in DD). The range of concentration at time 0 was from not detected to $4.1 \mathrm{ng} /$ $\mathrm{mL}$. Blood concentrations of MPH at time 1 and at time 6 rose as expected, as shown in Fig. 1. The median MPH blood concentration increased approximately ninefold from 


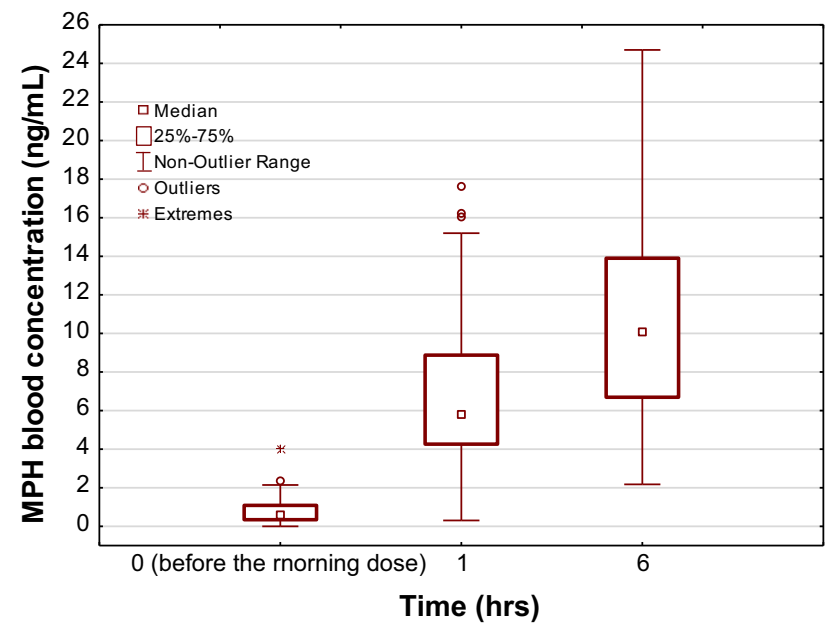

Fig. 1 Concentration-time profile of methylphenidate (MPH) blood concentrations in 50 patients before and after the morning dose (1 and $6 \mathrm{~h}$ ) of the osmotic release oral system (OROS)-MPH

time 0 to time 1 and 1.5 -fold from time 1 to time 6 . The distribution of MPH blood concentrations at time 1 and at time 6 in these patients is presented in Fig. 2.

Only in the adults, significant $(p<0.001)$ correlations were found between MPH blood concentration and morning dose (time $1, r_{\mathrm{s}}=0.63$ and time $6, r_{\mathrm{s}}=0.64$ ) as well as between MPH blood concentration and morning dose per body weight (time $1, r_{\mathrm{s}}=0.66$ and time $6, r_{\mathrm{s}}=0.69$ ). The correlation between blood concentration of MPH and RA was $r_{\mathrm{s}}=0.63$ at time 1 and $r_{\mathrm{s}}=0.69$ at time 6 .

No significant differences were found between patients from GP $(n=18)$ and DD $(n=16)$ in daily dose $(p=0.15)$, body weight $(p=0.41)$, daily dose per body weight $(p=0.57)$, MPH blood concentrations (time 1 , $p=0.06$; time $6, p=0.38$ ) or RA blood concentrations (time $1, p=0.05$; time $6, p=0.26$ ). Consistently, no significant differences in $[C /(D /$ weight $)]$ for $M P H$ and RA were found between patients from GP and DD at any time point.

Among adults, no significant differences were found between men $(n=22)$ and women $(n=12)$ in daily dose $(p=0.70)$, daily dose per body weight $(p=0.40)$, MPH blood concentrations (time $1, p=0.24$; time $6, p=0.23$ ) or RA blood concentrations (time $1, p=0.80$; time 6 , $p=0.15)$. Nonetheless, a significant difference in body weight was found $(p<0.001)$. However, no significant differences were found between adult men and women in $[\mathrm{C} /(\mathrm{D} /$ weight)] for MPH and RA at any time point. Among children, the number of girls was too low to be analyzed separately.

Between adults $(n=34)$ and children $(n=16)$, significant differences were found in daily dose $(p<0.001)$ and body weight $(p<0.001)$ but not in the dose adjusted for body weight $(p=1.0)$. Adults had higher median daily dose and higher median weight than children (72 vs $36 \mathrm{mg}$
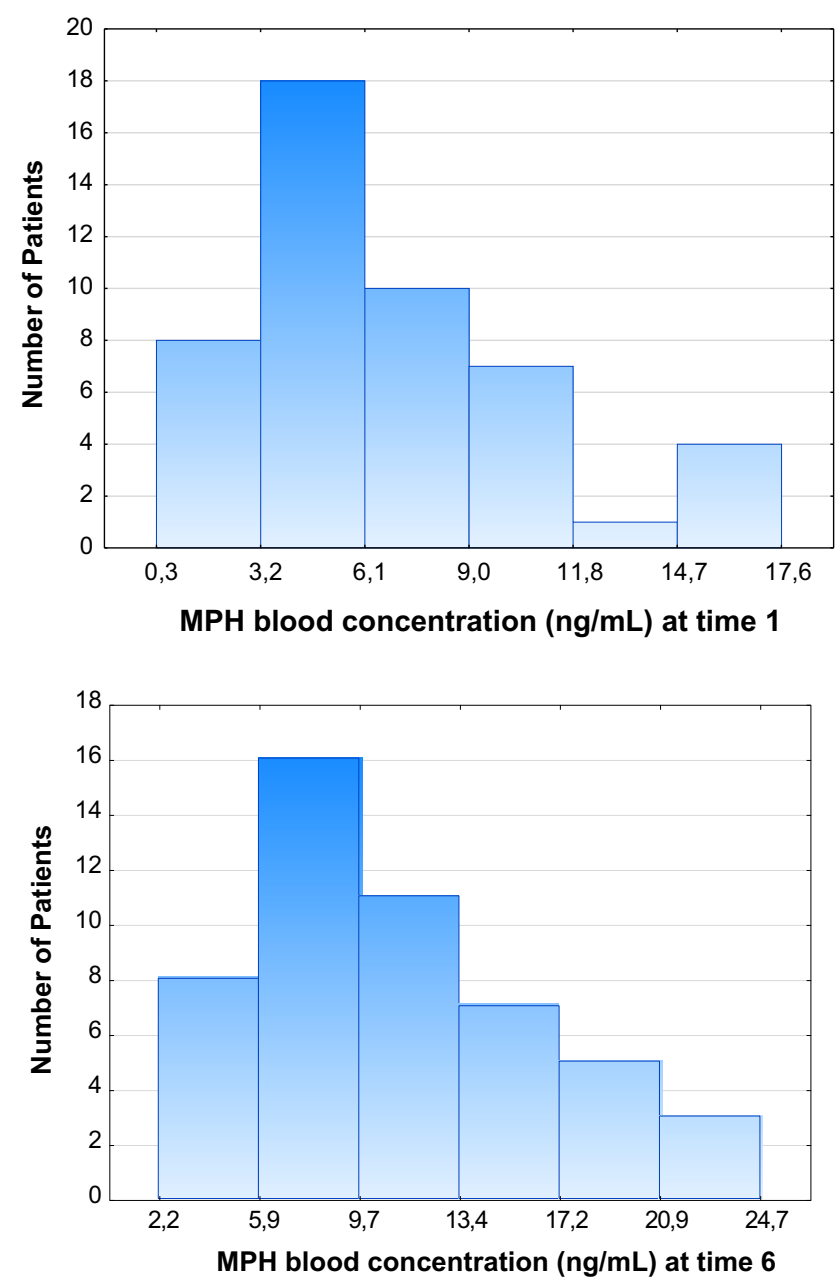

Fig. 2 Frequency distribution of blood methylphenidate (MPH) concentrations in 50 patients 1 and $6 \mathrm{~h}$ after the morning dose of the osmotic release oral system (OROS)-MPH

and $82 \mathrm{vs} 37 \mathrm{~kg}$, respectively). The prescribed median daily dose MPH was $1.0 \mathrm{mg} / \mathrm{kg}$ for adults and children. No significant differences were found between adults and children in MPH blood concentrations at any time point (time $1, p=0.67$; time $6, p=0.11)$ or in $[\mathrm{C} /(\mathrm{D} /$ weight $)]$ for MPH (time $1, p=0.09$; time $6, p=0.52$ ). The RA blood concentrations were lower in children than in adults, approximately $40 \%$ lower at time $1(p<0.05)$ and $12 \%$ lower at time $6(p=0.09)$. Consistently, significant differences were shown in $[\mathrm{C} /(\mathrm{D} /$ weight $)]$ for $\mathrm{RA}$ between adults and children at all time points $(p<0.05)$. Children had lower $[\mathrm{C} /(\mathrm{D} /$ weight $)]$ of RA blood concentrations than adults. As a consequence, the metabolic ratio (RA/MPH) was significantly lower in children than in adults at all time points (time $1, p<0.05$; time $6, p<0.001$ ). In all, an inter-individual variability was observed for $[\mathrm{C} /(\mathrm{D} /$ weight)] of both MPH blood concentrations (time 1, $\mathrm{CV}=55 \%$; time $6, \mathrm{CV}=39 \%$ ) and RA blood concentrations (time $1, \mathrm{CV}=44 \%$; time $6, \mathrm{CV}=29 \%$ ). 
Table 4 Methylphenidate blood concentrations $(>5$ patients per dose of OROS$\mathrm{MPH})$

\begin{tabular}{llll}
\hline Morning dose & $36 \mathrm{mg}$ & $54 \mathrm{mg}$ & $72 \mathrm{mg}$ \\
\hline Number $(n)$ of patients & 13 & 14 & 9 \\
Age $(\mathrm{y})$ & $12(9-69)$ & $18(11-67)$ & $45(21-54)$ \\
Male:Female, $n$ & $10: 3$ & $12: 2$ & $5: 4$ \\
Blood concentration at time 1 (1 h after the morning dose) & & \\
MPH ng/ml & $4.8(0.30-13)$ & $5.8(2.8-18)$ & $5.5(2.7-10)$ \\
RA ng/ml & $184(71-512)$ & $228(166-545)$ & $343(224-594)$ \\
RA/MPH & $40(22-326)$ & $46(16-88)$ & $70(38-120)$ \\
Blood concentration at time $6(6$ h after the morning dose) & & \\
MPH ng/ml & $11(3.0-20)$ & $9.2(5.5-22)$ & $9.3(2.9-15)$ \\
RA ng/ml & $352(193-470)$ & $402(303-659)$ & $475(307-814)$ \\
RA/MPH & $36(19-101)$ & $43(20-92)$ & $64(28-119)$ \\
\hline
\end{tabular}

Data are presented as median (range)

$M P H$ methylphenidate, $R A$ ritalinic acid, $O R O S-M P H$ osmotic release oral system (OROS)-MPH
No significant correlation was found between morning dose and RA/MPH ratio, neither at time $1\left(r_{\mathrm{s}}=0.22\right.$, $p=0.12)$ nor at time $6\left(r_{\mathrm{s}}=0.25, p=0.05\right)$. Similarly, correlation fails to be significant for morning dose per body weight and RA/MPH ratio. As shown in Table 3, the RA/ MPH ratio did not differ at time 1 and at time 6 in each group (GP, $p=1,0$; DD, $p=0.45$; CAP, $p=0.61$ ). On the other hand, the RA/MPH ratio at time 0 was significantly higher $(p<0.001)$ than at time 1 and at time 6 in all groups. The correlations between morning doses and metabolic ratio were $r_{\mathrm{s}}=0.22$ at time $1(p=0.13)$ and $r_{\mathrm{s}}=0.28$ at time $6(p=0.05)$.

The possible interaction of one particular drug on the blood concentration of MPH could not be shown because of the very few number of reports for a drug. However, we did not find any differences between the different ATC groups ( $>5$ patients/group) in daily dose per body weight $(p=0.14)$ or dose normalization for MPH (time 1, $p=0.70$; time $6, p=0.65$ ).

Among children, the number of caffeine consumers was too low to be analyzed separately. In the adults, the median daily dose per body weight was $1.1 \mathrm{mg} / \mathrm{kg}$ in high $(>0.5 \mathrm{~g})$ daily caffeine consumers $(n=14)$ and $0.88 \mathrm{mg} / \mathrm{kg}$ in nonuser or intermittent users $(n=20), p=0.05$. No significant differences were found in dose normalization for MPH between these groups. Further, no significant differences were found in daily dose per body weight or dose normalization for MPH neither between high $(>10 \mathrm{mg}$ ) daily nicotine consumers $(n=13)$ and nonuser-low nicotine consumers $(n=20)$ nor between daily alcohol consumers $(n=9)$ and not daily alcohol consumers $(n=25)$.

A stratification procedure was applied to increase PK data reliability. When dose-concentration correlation was calculated for dose concentrations with more than five patients per dose (Table 4), no relationship was found at time 1 and $\left(r_{\mathrm{s}}=0.08, p=0.64\right)$ and at time $6\left(r_{\mathrm{s}}=-\right.$ $0.05, p=0.76)$, neither for adults nor children. No significant differences were found between the doses in this subgroup for MPH blood concentration at time 1 $(p=0.63)$ and at time $6(p=0.91)$. The median MPH blood concentration (25th and 75th percentiles) was 5.4 (3.8-7.7) $\mathrm{ng} / \mathrm{mL}$ at time 1 and $9.3(6.6-13) \mathrm{ng} / \mathrm{mL}$ at time 6 . The median RA blood concentration was higher at dose $72 \mathrm{mg}$ intake, but it is worth pointing out that all patients with $72 \mathrm{mg}$ were adults, and $62 \%$ of patients with $36 \mathrm{mg}$ were children. The RA/MPH ratio was also higher but this difference was not significant.

\subsection{Oral Fluid}

Oral fluid (OF) samples were taken in parallel to the blood samples (Table 5). MPH in OF was found highly instable, and the OF had to be centrifuged immediately and frozen in $-70{ }^{\circ} \mathrm{C}$ until analysis to prevent degradation. Many patients (not only the children) also had difficulties providing enough $\mathrm{OF}$, and in several instances, the $\mathrm{OF}$ was contaminated with blood from gingival bleeding. In every OF sample, MPH concentrations were higher (median about fourfold) than in blood. Conversely, RA concentration in $\mathrm{OF}$ was about 25-fold lower than in blood.

Intra-individual patient comparison showed significant $(p<0.001)$ correlations between MPH concentrations in OF and in blood at all time points (time $0, r_{\mathrm{s}}=0.53$; time $1, r_{\mathrm{s}}=0.69$; time $\left.6, r_{\mathrm{s}}=0.54\right)$ as well as between RA concentrations in $\mathrm{OF}$ and in blood (time $0, r_{\mathrm{s}}=0.68$; time $1, r_{\mathrm{s}}=0.77$; time $\left.6, r_{\mathrm{s}}=0.63\right)$. However, a high interindividual patient variability of the OF-to-blood ratio of $\mathrm{MPH}\left(\mathrm{MPH}_{\mathrm{S}} / \mathrm{MPH}\right)$ was found at time $0(\mathrm{CV} 130 \%)$, at time 1 (CV $131 \%)$, and at time $6(\mathrm{CV} 100 \%)$ as well as of the OF-to-blood ratio of RA ( $\left.\mathrm{RA}_{S} / \mathrm{RA}\right)$ at all time points 
Table 5 Methylphenidate analysis in oral fluid

\begin{tabular}{|c|c|c|c|c|}
\hline & GP & DD & CAP & All patients \\
\hline Number $(n)$ of patients & 22 & 16 & 21 & 59 \\
\hline \multicolumn{5}{|c|}{ Concentration at time 0 (trough concentration) } \\
\hline $\mathrm{MPH}_{\mathrm{S}} / \mathrm{MPH}$ & $5.4(1.8-54)$ & $3.1(1.1-11)$ & $4.5(1.6-8.2)$ & $4.5(1.1-54)$ \\
\hline $\mathrm{RA}_{S} / \mathrm{RA}$ & $0.04(0.02-0.35)$ & $0.03(0.01-0.08)$ & $0.04(0.02-0.43)$ & $0.04(0.01-0.43)$ \\
\hline \multicolumn{5}{|c|}{ Concentration at time 1 ( $1 \mathrm{~h}$ after the morning dose) } \\
\hline $\mathrm{MPH}_{\mathrm{S}} / \mathrm{MPH}$ & $3.9(1.5-54)$ & $4.3(1.5-18)$ & $3.6(1.6-12)$ & $3.8(1.5-54)$ \\
\hline $\mathrm{RA}_{S} / \mathrm{RA}$ & $0.03(0.02-0.25)$ & $0.02(0.01-0.06)$ & $0.03(0.01-0.06)$ & $0.03(0.01-0.25)$ \\
\hline \multicolumn{5}{|c|}{ Concentration at time 6 ( $6 \mathrm{~h}$ after the morning dose) } \\
\hline $\mathrm{MPH}_{\mathrm{S}} / \mathrm{MPH}$ & $4.3(1.7-29)$ & $4.7(2.0-29)$ & $2.8(1.1-7.6)$ & $3.8(1.1-29)$ \\
\hline $\mathrm{RA}_{S} / \mathrm{RA}$ & $0.05(0.02-0.21)$ & $0.04(0.02-0.09)$ & $0.03(0.02-0.05)$ & $0.04(0.02-0.21)$ \\
\hline
\end{tabular}

Data are presented as median (range) unless specified otherwise

$M P H_{S}$ methylphenidate concentration in oral fluid, $R A_{S}$ ritalinic acid concentration in oral fluid, $M P H$ methylphenidate concentration in blood, $R A$ ritalinic acid concentration in blood, GP General Psychiatry, $D D$ Department of Dependency, CAP Child and Adolescent Psychiatry (time 0, CV $122 \%$; time 1, CV $89 \%$; time 6, CV $69 \%$ ). Also, in the patients that took OROS-MPH, no significant correlations were found between morning dose and $\mathrm{MPH}$ concentrations in OF at time $1\left(r_{\mathrm{s}}=0.18, p=0.21\right)$ and at time $6\left(r_{\mathrm{s}}=0.27, p=0.06\right)$.

The $\mathrm{MPH}_{\mathrm{S}} / \mathrm{MPH}$ ratio did not vary at the different time points $(p=0.29)$. On the other hand, the $\mathrm{RA}_{\mathrm{S}} / \mathrm{RA}$ ratio varied between the time points $(p<0.001)$. No significant differences were shown between the three patient groups for OF-to-blood ratio of MPH and RA.

\section{Discussion}

This naturalistic study presents a detailed description of MPH and RA blood concentrations in child and adult patients with well-adjusted MPH treatment for ADHD. Good clinical effect on symptoms was achieved by careful dose titration performed with the help of questionnaires and computer-based assessment. The findings show that the median daily dose of MPH per $\mathrm{kg}$ body weight was similar between all three patient groups (approximately $1.0 \mathrm{mg}$ / $\mathrm{kg}$ ). This is well in accordance with the research literature that suggests titrating MPH to $1.0 \mathrm{mg} / \mathrm{kg}$ for the best behavioral response in children [24]. Thus, adults, as they normally weigh more than children, require a higher daily dose of MPH per day than children do. This study supports the advice from clinical guidelines to adjust the MPH dose through stepwise titration to at least $1.0 \mathrm{mg} \mathrm{MPH}$ per $\mathrm{kg}$ body weight and possibly up to approximately $1.2-2.2 \mathrm{mg} /$ $\mathrm{kg}$, according to our data. This is well in accordance with the findings from the MTA study in which carefully monitored medication clearly outplaced less rigorous practice [25].
The need in clinical routine for a carefully titrated personalized dose is reflected in the large variability between patients of the administered MPH dose (18-180 mg/day). Despite this, in the cohort of patients which took OROSMPH in the morning of the study day, the $[\mathrm{C} /(\mathrm{D} /$ weight $)]$ of MPH in blood did not differ between the three groups studied. The concentrations of MPH in blood were after $1 \mathrm{~h}, 5.4(3.8-7.7) \mathrm{ng} / \mathrm{mL}$ and after 6 h, 9.3 (6.6-13) ng/mL. These concentrations are in accordance with other studies that reported therapeutic concentrations in blood [26, 27]. Considering this, we would suggest that blood concentrations of MPH might be used for dose optimization to ensure optimal clinical benefit of MPH treatment. This may be supported by positron emission tomography (PET) studies, which found a correlation between blood concentration of MPH and dopamine transporter (DAT) occupancy, the main target of MPH in the brain [28-30]. The clinical use of blood concentrations might be also used to monitoring the prescribed dose, e.g., in patients requiring higher than approved dosing of $\mathrm{MPH}$, since we find an association between morning dose and MPH blood concentrations in adults. A controlled setting might also contribute to the adherence of MPH treatment.

In this study, patients with a history of drug abuse did not require significantly higher doses of $\mathrm{MPH}$ to receive good ADHD symptom control. This is a good argument in reply to clinicians who argue that MPH treatment of former drug abusers is nothing more than substitution treatment for their drug abuse [31]. We show that the effective MPH doses for former drug abuser patients from DD were not higher than for patients in GP.

The metabolic ratio (RA/MPH) was similar for adults but significantly lower in children. Metabolic ratio is considered as a measure of metabolic clearance. The 
different patterns between adults and children may possibly be due to maturation effects of carboxylesterase with low levels of CES expression during early developmental stages [16, 31, 32]. However, clearance of MPH and RA via other pathways and elimination of the metabolite will also affect the metabolic ratio. The study showed a timedependent increase of the RA/MPH ratio after the highest MPH blood concentration at time 6 to the next dose at time 0 , possibly due to the slower elimination of RA than MPH [33].

OROS-MPH was developed with the aim to without compromise of effectiveness not cause acute pharmacodynamic tolerance. The delivery system was designed to provide successively increasing blood concentrations with a 12-h duration across the day [34]. We confirmed such delayed increase since we showed MPH blood concentrations increased 1 and $6 \mathrm{~h}$ after a morning dose. However, some patients claim that the effect of their medication fades away much sooner than the expected 10-12 h. Some adult patients took OROS-MPH more than once a day $(41 \%)$. A study in prison inmates with ADHD showed that OROS-MPH intake in the morning and at noon maintained symptoms relief throughout the day [35]. It is conceivable that these patients react to that their blood concentration no longer increase after a few hours and therefore need a booster dose since the clinical effectiveness could be more related to the ascending profile than the flat profile $[29,36]$. At time 0 (trough concentration), the blood concentrations of MPH were expected to not be detected (below the LOQ) due to the short half-life of the MPH and the overnight washout period. However, it is noteworthy that MPH blood concentrations in $86 \%$ of patients in our study remained detectable until the following morning dose. In fact, median trough blood concentrations of MPH were $6 \%$ of the median highest blood concentrations of MPH. A relatively constant MPH blood concentration could be a possible risk factor for developing pharmacodynamic tolerance [34, 36].

Many persons with ADHD consume large amount of dopamine active agents, such as nicotine in cigarettes and caffeine in coffee and soft drinks, as well as alcohol. In this study, all adults reported consumption of at least one dopamine active agent. About one-third of the children reported consumption of caffeine. Some studies show that caffeine may induce pharmacodynamic tolerance [37, 38]. Furthermore, it is known that the transesterification of MPH after coadministration with ethanol form ethylphenidate, a selective dopaminergic agonist [39, 40]. Though, in our data, no differences were found between patients regarding high consumption or not of caffeine, nicotine or alcohol.

As expected, the optimal oral MPH dose per day differed between patients. This variability might be due to differences in absorption of MPH that has been shown to vary between 10 and $52 \%$ [41], as well as due to differences in metabolism [42, 43]. Since polymorphisms for the principal enzyme responsible for the de-esterification of MPH to RA (CES1) have a low frequency, it is a less plausible cause for this variability. But, CES1 polymorphisms might be important for individual carriers that may require lower doses of MPH for symptom reduction or as regards toxicities. Further, polymorphisms in DAT and dopamine D4 receptor genes could affect the clinical effect of a given dose of MPH, but previous pharmacogenetics studies are limited [44].

Finally, we investigated whether OF could replace blood as a matrix for analysis of MPH concentration for the monitoring of MPH treatment, since OF as sampling matrix could be an attractive alternative for a more convenient sampling without the need for venepuncture. MPH concentrations were much higher in OF than in blood, probably due to active secretion similar to other amphetaminelike compounds [45, 46]. Conversely, RA concentrations in OF showed an opposite trend. RA does not readily pass into OF, and thus, measured concentrations were low. Although a correlation was found between MPH concentration in OF and in blood within the same patient, in agreement with the literature [45], there was very large variation of the $\mathrm{MPH}_{\mathrm{S}} / \mathrm{MPH}$ between patients. We would, thus, not advocate OF analysis of MPH as a safe method for monitoring of MPH treatment. MPH concentration in OF may be used for follow-up of the treatment over time in a single patient provided that the $\mathrm{MPH}_{\mathrm{S}} / \mathrm{MPH}$ ratio has been determined at start. However, the stability of MPH in OF samples must be ensured. It is possible that the same methodological problems in OF analysis of MPH that we encountered could explain the puzzling findings from the MTA study of discrepancies between parents' reports of good compliance with medication and MPH concentrations not detectable in OF analysis [19].

This study has the advantage of a naturalistic study, i.e., a reflection "real life" circumstances. There are some limitations but also some obvious strengths. The study displays the panorama in the everyday clinical setting with patients with well-adjusted doses to provide clinical good symptom control. Thus, this study reports blood concentration ranges of MPH and RA in normal clinical settings, analyzing a heterogenic population never found in preregistration clinical trials. MPH blood and OF analyses were completed in the same laboratory with a well-developed and stable method for quantitative analysis that is proven to cover clinically relevant concentrations of MPH and RA. The small size of the investigated group neither enables comparisons between sexes nor between different co-medications or consumption of dopamine active agents between the patients. Together with the limited geographical distribution of the recruited subjects, this limitation makes the study prone to a type II error, and thus reduces 
the soundness of dose comparisons across groups. Also, dose allocation was not randomized, so, confounding factors must be considered. Lastly, the presence of ethylphenidate and its possible significance was not investigated.

\section{Conclusions}

Adjusting the prescribed MPH dose to approximately $1.0 \mathrm{mg} / \mathrm{kg}$ body weight via stepwise dose titration is a reliable clinical approach, valid for both children and adults even with a history of drug abuse. MPH blood concentrations in our study were within the range of concentrations reported to be therapeutic for ADHD. Measuring blood concentrations of MPH could be used for individual dose optimization and for monitoring of the prescribed dose, e.g., if patients are craving for high doses of MPH. Relying only on the outcome in OF cannot be recommended for evaluation of accurate MPH concentrations for treatment monitoring.

More studies are necessary to evaluate possible differences in PK of MPH between the sexes and among consumers of dopamine active agents in this population. It would be desirable to confirm the blood concentration ranges of MPH and RA reported in this study to ensure optimal clinical benefit of MPH treatment as well as the possible role of the metabolite ethylphenidate.

Acknowledgments The authors would like to sincerely thank all the children and adults who participated in this study, and nurses Isabelle Lewung and Ingela Jacobsson, as well as assistant nurse Annette Straarup who assisted in taking blood and oral fluid samples.

Authors contribution P.A. Gustafsson and M. Josefsson designed the study and wrote the protocol together with I. Rydberg. O. Hollertz, T. Trygg, P. Woxler and I. Rydberg managed the data collection and preparation of data in accordance with the protocol. M. Josefsson and I. Rydberg managed the MPH analyses. M.D. Chermá and P.A. Gustafsson undertook the statistical analyses. M.D. Chermá, P.A. Gustafsson and M. Josefsson performed the literature search. M.D. Chermá and P.A. Gustafsson wrote the first draft of the manuscript. All authors contributed to the discussion and have approved the final manuscript. All authors approved the final version of the manuscript, and agree to be accountable for this work.

\section{Compliance with Ethical Standards}

Funding Grants from the following research funds are acknowledged: Swedish Medical Research Council (No. 2009-4740), Medical Research Council of Southeast Sweden (FORSS-12147 and FORSS155281). The funding sources had no further role in study design, collection, analysis and interpretation of data, the writing of the report, or the decision to submit the paper for publication.

Conflict of interest MDC, MJ, IR, PW, TT, OH and PAG declare no conflicts of interest.
Ethical approval All procedures performed in studies involving human participants were in accordance with the ethical standards of the institutional and/or national research committee and with the 1964 Helsinki declaration and its later amendments or comparable ethical standards. The Ethics Committee of the Medical Faculty of Linköping University, Sweden (Dnr M92-07), the Swedish Medical Products Agency and the Swedish Data Inspection Board (Dnr 1405-2007) approved the collection of patient samples. All patients gave written as well as oral informed consent before inclusion in the study.

Open Access This article is distributed under the terms of the Creative Commons Attribution-NonCommercial 4.0 International License (http://creativecommons.org/licenses/by-nc/4.0/), which permits any noncommercial use, distribution, and reproduction in any medium, provided you give appropriate credit to the original author(s) and the source, provide a link to the Creative Commons license, and indicate if changes were made.

\section{References}

1. NICE-2008. National Institute for Health and Care Excellence. http://www.nice.org.uk/guidance/CG72. Accessed 1 Apr 2014.

2. Dalsgaard S, Nielsen HS, Simonsen M. Five-fold increase in national prevalence rates of attention-deficit/hyperactivity disorder medications for children and adolescents with autism spectrum disorder, attention-deficit/hyperactivity disorder, and other psychiatric disorders: a Danish register-based study. J Child Adolesc Psychopharmacol. 2013;23(7):432-9. doi:10.1089/cap.2012.0111.

3. National Board of Health and Welfare. http://www. socialstyrelsen.se/statistik/statistikdatabas/lakemedel. Accessed 27 April 2016.

4. Medical Products Agency Sweden. http://www.lakemedelsverket. se/malgrupp/Halso — sjukvard/Behandlings-rekommendationer/ Behandlingsrekommendation-listan/ADHD/. Accessed 26 Nov 2013.

5. Medical Products Agency Sweden. http://www.lakemedelsverket. se/Alla-nyheter/NYHETER-2012/Lakemedelsansvandningenvid-ADHD-foljs-lopande/. Accessed 27 Nov 2013.

6. Faraj BA, Israili ZH, Perel JM, Jenkins ML, Holtzman SG, Cucinell SA, et al. Metabolism and disposition of methylphenidate-14C: studies in man and animals. J Pharmacol Exp Therapeut. 1974;191(3):535-47.

7. Nemoda Z, Angyal N, Tarnok Z, Gadoros J, Sasvari-Szekely M. Carboxylesterase 1 gene polymorphism and methylphenidate response in ADHD. Neuropharmacology. 2009;57(7-8):731-3. doi:10.1016/j.neuropharm.2009.08.014.

8. Thomsen R, Rasmussen HB, Linnet K, INDICES Consortium. Enantioselective determination of methylphenidate and ritalinic acid in whole blood from forensic cases using automated solidphase extraction and liquid chromatography-tandem mass spectrometry. J Anal Toxicol. 2012;36(8):560-8. doi:10.1093/jat/ bks065.

9. Patrick KS, Kilts CD, Breese GR. Synthesis and pharmacology of hydroxylated metabolites of methylphenidate. J Med Chem. 1981;24(10):1237-40.

10. Meyer MC, Straughn AB, Jarvi EJ, Patrick KS, Pelsor FR, Williams RL, et al. Bioequivalence of methylphenidate immediaterelease tablets using a replicated study design to characterize intrasubject variability. Pharm Res. 2000;17(4):381-4.

11. Kimko HC, Cross JT, Abernethy DR. Pharmacokinetics and clinical effectiveness of methylphenidate. Clin Pharmacokinet. 1999;37(6):457-70. doi:10.2165/00003088-199937060-00002. 
12. Banaschewski T, Coghill D, Santosh P, Zuddas A, Asherson P, Buitelaar $\mathrm{J}$, et al. Long-acting medications for the hyperkinetic disorders. A systematic review and European treatment guideline. Eur Child Adolesc Psychiatry. 2006;15(8):476-95. doi:10.1007/ s00787-006-0549-0.

13. National Board of Health and Welfare. http://www. socialstyrelsen.se/publikationer2012/2012-10-30. Accessed 27 Nov 2013.

14. Stevens JR, George RA, Fusillo S, Stern TA, Wilens TE. Plasma methylphenidate concentrations in youths treated with high-dose osmotic release oral system formulation. J Child Adolesc Psychopharmacol. 2010;20(1):49-54. doi:10.1089/cap.2008.0128.

15. Maldonado R. Comparison of the pharmacokinetics and clinical efficacy of new extended-release formulations of methylphenidate. Expert Opin Drug Metab Toxicol. 2013;9(8):1001-14. doi:10.1517/17425255.2013.786041.

16. Wigal SB, Gupta S, Greenhill L, Posner K, Lerner M, Steinhoff K, et al. Pharmacokinetics of methylphenidate in preschoolers with attention-deficit/hyperactivity disorder. J Child Adolesc Psychopharmacol. 2007;17(2):153-64. doi:10.1089/cap.2007.0043.

17. Parasrampuria DA, Schoedel KA, Schuller R, Gu J, Ciccone P, Silber SA, et al. Assessment of pharmacokinetics and pharmacodynamic effects related to abuse potential of a unique oral osmotic-controlled extended-release methylphenidate formulation in humans. J Clin Pharmacol. 2007;47(12):1476-88. doi:10. 1177/0091270007308615.

18. Ermer JC, Adeyi BA, Pucci ML. Pharmacokinetic variability of long-acting stimulants in the treatment of children and adults with attention-deficit hyperactivity disorder. CNS Drugs. 2010;24(12):1009-25. doi:10.2165/11539410-000000000-00000.

19. Pappadopulos E, Jensen PS, Chait AR, Arnold LE, Swanson JM, Greenhill LL, et al. Medication adherence in the MTA: saliva methylphenidate samples versus parent report and mediating effect of concomitant behavioral treatment. J Am Acad Child Adolesc Psychiatry. 2009;48(5):501-10. doi:10.1097/CHI. 0b013e31819c23ed.

20. Qbtech. Quantitative behaviour technology. https://www.qbtech. com/. Accessed 18 Feb 2015.

21. Test of Variables of Attention (T.O.V.A. ${ }^{\circledR}$ ) http://www.tovatest. com/. Accessed 18 Feb 2015.

22. Wolraich ML, Greenhill LL, Pelham W, Swanson J, Wilens T, Palumbo D, et al. Randomized, controlled trial of oros methylphenidate once a day in children with attention-deficit/hyperactivity disorder. Pediatrics. 2001;108(4):883-92.

23. Josefsson M, Rydberg I. Determination of methylphenidate and ritalinic acid in blood, plasma and oral fluid from adolescents and adults using protein precipitation and liquid chromatography tandem mass spectrometry-a method applied on clinical and forensic investigations. $\mathrm{J}$ Pharm Biomed Anal. 2011;55(5):1050-9. doi:10.1016/j.jpba.2011.03.009.

24. Sprague RL, Sleator EK. Methylphenidate in hyperkinetic children: differences in dose effects on learning and social behavior. Science. 1977;198(4323):1274-6.

25. Greenhill LL, Abikoff HB, Arnold LE, Cantwell DP, Conners CK, Elliott G, et al. Medication treatment strategies in the MTA Study: relevance to clinicians and researchers. J Am Acad Child Adolesc Psychiatry. 1996;35(10):1304-13. doi:10.1097/ 00004583-199610000-00017.

26. Schulz M, Schmoldt A. Therapeutic and toxic blood concentrations of more than 800 drugs and other xenobiotics. Pharmazie. 2003;58(7):447-74.

27. Hiemke C, Baumann P, Bergemann N, Conca A, Dietmaier O, Egberts K, et al. AGNP consensus guidelines for therapeutic drug monitoring in psychiatry: update 2011. Pharmacopsychiatry. 2011;44(6):195-235. doi:10.1055/s-0031-1286287.
28. Spencer TJ, Biederman J, Ciccone PE, Madras BK, Dougherty $\mathrm{DD}$, Bonab AA, et al. PET study examining pharmacokinetics, detection and likeability, and dopamine transporter receptor occupancy of short- and long-acting oral methylphenidate. Am J Psychiatry. 2006;163(3):387-95. doi:10.1176/appi.ajp.163.3.387.

29. Swanson JM, Volkow ND. Pharmacokinetic and pharmacodynamic properties of stimulants: implications for the design of new treatments for ADHD. Behav Brain Res. 2002;130(1-2):73-8.

30. Spencer TJ, Bonab AA, Dougherty DD, Martin J, McDonnell T, Fischman AJ. A PET study examining pharmacokinetics and dopamine transporter occupancy of two long-acting formulations of methylphenidate in adults. Int J Mol Med. 2010;25(2):261-5.

31. Mariani JJ, Levin FR. Treatment strategies for co-occurring ADHD and substance use disorders. Am J Addict/Am Acad Psychiatr Alcohol Addict. 2007;16 Suppl 1:45-54. doi:10.1080/ 10550490601082783 (quiz 5-6).

32. Zhu HJ, Appel DI, Jiang Y, Markowitz JS. Age- and sex-related expression and activity of carboxylesterase 1 and 2 in mouse and human liver. Drug Metab Dispos Biol Fate Chem. 2009;37(9):1819-25. doi:10.1124/dmd.109.028209.

33. Wargin W, Patrick K, Kilts C, Gualtieri CT, Ellington K, Mueller RA, et al. Pharmacokinetics of methylphenidate in man, rat and monkey. J Pharmacol Exp Therapeut. 1983;226(2):382-6.

34. Markowitz JS, Straughn AB, Patrick KS. Advances in the pharmacotherapy of attention-deficit-hyperactivity disorder: focus on methylphenidate formulations. Pharmacotherapy. 2003;23(10):1281-99.

35. Ginsberg Y, Lindefors N. Methylphenidate treatment of adult male prison inmates with attention-deficit hyperactivity disorder: randomised double-blind placebo-controlled trial with open-label extension. Br J Psychiatry J Mental Sci. 2012;200(1):68-73. doi:10.1192/bjp.bp.111.092940.

36. Swanson J, Gupta S, Guinta D, Flynn D, Agler D, Lerner M, et al. Acute tolerance to methylphenidate in the treatment of attention deficit hyperactivity disorder in children. Clin Pharmacol Ther. 1999;66(3):295-305. doi:10.1016/S0009-9236(99)70038-X.

37. Jain R, Holtzman SG. Caffeine induces differential cross tolerance to the amphetamine-like discriminative stimulus effects of dopaminergic agonists. Brain Res Bull. 2005;65(5):415-21. doi:10.1016/j.brainresbull.2005.02.024.

38. Garrett BE, Griffiths RR. The role of dopamine in the behavioral effects of caffeine in animals and humans. Pharmacol Biochem Behav. 1997;57(3):533-41.

39. Patrick KS, Corbin TR, Murphy CE. Ethylphenidate as a selective dopaminergic agonist and methylphenidate-ethanol transesterification biomarker. J Pharm Sci. 2014;103(12):3834-42. doi:10.1002/jps.24202.

40. Markowitz JS, DeVane CL, Boulton DW, Nahas Z, Risch SC, Diamond $\mathrm{F}$, et al. Ethylphenidate formation in human subjects after the administration of a single dose of methylphenidate and ethanol. Drug Metab Dispos Biol Fate Chem. 2000;28(6):620-4.

41. Duong S, Chung K, Wigal SB. Metabolic, toxicological, and safety considerations for drugs used to treat ADHD. Expert Opin Drug Metab Toxicol. 2012;8(5):543-52. doi:10.1517/17425255.2012.671295.

42. Merali Z, Ross S, Pare G. The pharmacogenetics of carboxylesterases: CES1 and CES2 genetic variants and their clinical effect. Drug Metab Drug Interact. 2014;29(3):143-51. doi:10.1515/dmdi-2014-0009.

43. Zhu HJ, Patrick KS, Yuan HJ, Wang JS, Donovan JL, DeVane $\mathrm{CL}$, et al. Two CES1 gene mutations lead to dysfunctional carboxylesterase 1 activity in man: clinical significance and molecular basis. Am J Hum Genet. 2008;82(6):1241-8. doi:10. 1016/j.ajhg.2008.04.015.

44. Froehlich TE, McGough JJ, Stein MA. Progress and promise of attention-deficit hyperactivity disorder pharmacogenetics. CNS 
Drugs. 2010;24(2):99-117. doi:10.2165/11530290-00000000000000.

45. Schepers RJ, Oyler JM, Joseph RE Jr, Cone EJ, Moolchan ET, Huestis MA. Methamphetamine and amphetamine pharmacokinetics in oral fluid and plasma after controlled oral methamphetamine administration to human volunteers. Clin Chem. 2003;49(1):121-32.
46. de la Torre R, Farre M, Navarro M, Pacifici R, Zuccaro P, Pichini S. Clinical pharmacokinetics of amfetamine and related substances: monitoring in conventional and non-conventional matrices. Clin Pharmacokinet. 2004;43(3):157-85. doi:10.2165/ 00003088-200443030-00002. 